American Journal of Immunology 3 (2): 25-30, 2007

ISSN 1553-619X

(C) 2007 Science Publications

\title{
Correlation Between MMP-3, TIMP-3 Expression and Neuronal Apoptosis After Ischemia - Reperfusion Injury in Rates
}

\author{
${ }^{1}$ Zi Xiaohong, ${ }^{1}$ Mutasem Abuhamed, ${ }^{2}$ Yuan Yi, ${ }^{1}$ Xu Haiqing, ${ }^{1}$ Lei Lifang, ${ }^{1}$ Guo Ke and ${ }^{2}$ Yang Qidong \\ ${ }^{1}$ Department of Neurology, theThird affiliated, Xiangya Hospital, Central South University, Changsha \\ 410013, Hunan, P.R. China \\ ${ }^{2}$ Department of Neurology, the First affiliated, Xiangya Hospital, Central South University, Changsha \\ 410013, Hunan, and P.R. China
}

\begin{abstract}
Matrix metalloproteinases (MMPs) play a central role in many biological processes, such as embryogenesis, normal tissue remodeling, wound healing, and angiogenesis. How MMP3, TIMP3 expression and neuronal apoptosis (Fas, Fas- $\mathrm{L}$ and $\mathrm{Bcl}$ ) may provide detrimental or beneficial actions during the injury and repair processes after cerebral ischemia-reperfusion injury in rates was studied. Adult rats underwent middle cerebral artery occlusion (MCAO) by the suture method. The expression of mRNA for TIMP-3, MMP-3, and neuronal apoptosis -were estimated in samples of Brain cortices of the ischemic penumbra (IPZ) and the core ischemic zone (ICZ) from70 Rates with Ischemic control group (ICG), 10 sham-operated group (SOG) and 60 Ischemic $\beta$-sodium aescinate intervention group $(\mathrm{I} \beta \mathrm{G})$ using the reverse-transcriptasepolymerase chain reaction with a synthetic multicompetitor standard. Also the amounts of neuronal apoptosis positive cells were evaluated by TUNEL assay. I $\beta G$ expressed significantly TIMP-3, MMP-3 mRNA more than the ICG..Also in the ischemic zone Bcl-2 mRNA was strikingly increased whereas Fas and Fas-L mRNA was considerably decreased. At same time, the amount of apoptosis cells was maximally increased at 3 hours and was lowest decreased at 72 hours after reperfusion. Altogether, these results strongly suggest that inappropriate MMP-3 expression combined with increased TIMP-3, the ratio of apoptotic cells shows positive correlation with TIMP-3, negative correlation with MMP-3 and MMP-3, TIMP-3 Expression might modulate the process of type I and type II neuronal apoptosis through FAS pathway.
\end{abstract}

Key Words: Ischemica-reperfusion injury, neuronal apoptosis, matrix metalloproteinase, tissue inhibitors of matrix metalloproteinase.

\section{INTRODUCTION}

Ischemical reperfusion injury induces a series of cytokine cascade reaction, which cause neurons necrosis or apoptosis. The cerebral ischemia tissue can induce the expression of death receptors, such as Fas and TNF- $\alpha$. Once binding with the corresponding death inducing ligand, it will activate caspase protein cascade reaction and result in neuronal apoptosis ultimately ${ }^{[1,2]}$ Reperfusion of ischemic tissue after the infarct reduces ischemic damage. Several mechanisms have been proposed to explain the tissue damage associated with reperfusion of ischemic tissue. Reintroduction of oxygenated blood into the damaged region enhances the production of free radicals, recruits neutrophils and macrophages, and releases proteases ${ }^{[3,4]}$. Proteases take apart cellular structures in many neurological diseases. Neutral proteases, including cysteine, serine, and metalloproteinase (MP) gene families, have complex functions under normal and pathological conditions. Metalloproteinases (MPs), which include the matrix metalloproteinases (MMPs) and ADAMs (a disintegrin and metalloproteinase domain) protease gene families, act as sheddases in the removal of cell surface death receptors and death-inducing ligands ${ }^{[5]}$. Tissue inhibitors of metalloproteinases (TIMPs) are specific inhibitors of matrixins that participate in controlling the local activities of MMPs in tissues ${ }^{[6]}$. It has been confirmed that the intercommunion between the membrane death receptors and the death inducing ligand is an important

Corresponding authors: Zi Xiaohong, Department of Neurology, theThird affiliated, Xiangya Hospital, Tongzi Po 172\#, Changsha 410013, Hunan, P.R. China Fax: +86 0731 8630901, mobile 008613607430960 
process, which can induce cell apoptosis. MMP-3 and MMP-7 may degrade death receptors independently and inhibit neuronal apoptosis; while TIMP-3 can bind with MMP-3 to produce a complex, which can inhibit the hydrolyzation of MMP-3 and promote apoptosis ${ }^{[7,8]}$. The present series of experiments were performed to determine whether there was differential expression of TIMP-3, MMP-3 and neural apoptosis in cerebral ischemia reperfusion zone.

\section{MATERIALS AND METHODS}

Ischemia-Reperfusion Protocol and Grouping: The study was approved by the University of Central South Animal Care Committee and conformed to the National Institutes of Health Guidelines for use of animals in research. Adult Wistar rats at 12-16 weeks of age weighing 250 to $320 \mathrm{~g}$, were anesthetized with $1.5 \%$ halothane in $70 \%$ nitrous oxide and $30 \%$ oxygen. MCAO was done by insertion of an intraluminal nylon suture with a bulb on the end. Neck vessels were exposed through a midline incision, and branches of the right external carotid artery were isolated and ligated. A 6-0 silk suture was loosely tied around the external carotid artery stump. A 4-0-monofilament nylon suture was introduced into the external carotid and advanced into the MCA. A silk suture around the stump was tied down onto the thread with the end of the thread protruding slightly. Reperfusion was achieved by slowly pulling the thread back ${ }^{[9]}$.

A total of 120 Wistar rat were randomly assigned to three groups. 60 rates of IBG had undergone 3 hours of MCAO with reperfusion for 3, 6, 12, 24, 48,72(O3Rxh) hours and received an intraabdominal cavity (i.c.) injection of sodium aescinat $(5 \mathrm{mg} / \mathrm{kg} / 24$ hour $)$. SOG rats (10) dura was opened over the MCA, but the artery was not occluded. ICG rats had undergone 3 hours of MCAO (O3R0h), Ischemical 3hours with reperfusion for 3, 6, 12, 24, 48,72 hours (O3Rxh).

Analysis of Brain Tissue Injury: Two rates were selected randomly from each group. The brain was removed and frozen in 2-methylbutane cooled to $20^{\circ} \mathrm{C}$ for 20 minutes. A 3-mm tissue section was removed from a region approximately $3 \mathrm{~mm}$ away from the tip of the frontal lobe, incubated with $2 \%$ Triphenyltetrazolium chloride (TTC) solution at $37^{\circ} \mathrm{C}$ for $30 \mathrm{~min}$ and fixed in $4 \%$ paraformaldehyde (PFA) for $6 \mathrm{~h}$. The normal brain tissue presents red and ischemic presents pale.

Reverse Transcriptase Polymerase Chain Reaction (RT-PCR) Analyzes:(1) the primers of TIMP-3, MMP3 , and $\beta$-actin were designed by an online primer design programn(e.g.,Primer3: http://www.genome.wi.mit.edu/cgibin/primer/primer3_ www.cgi). Fas, Fas-L and Bcl-2 were produced by Wetzel $\mathrm{M}$ and Ursula FM design $[7,8]$ as shown in Table1. (2) After the rats were killed, the brains were removed and immediately frozen to $-20^{\circ} \mathrm{C}$ for $15-20$ mins, and the cortex would be denuded at the right side of brain, which is $7-11 \mathrm{~mm}$ away from the olfactory bulb's most advanced end, then chose a upper $1 / 3$ (ischemic penumbra zone) and a lower $2 / 3$ (ischemic core zone) portions of the brain tissue from arrow-form splitto perisylvian separately [9], products are conserved in the liquid nitrogen. (3) The total RNA in brains was extracted according to manufacturer's protocol (U.S.A Gibco BRL Company); products were conserved in $-20^{\circ} \mathrm{C}$. (4) Reverse transcription reactions are performed with $5 \mathrm{ul}$ of total RNA and primer according to manufacturer's protocol (U.S.A MBI Company); products are conserved in $-20^{\circ} \mathrm{C}$ (5) the suitest condition of PCR as shown in Table 1; (6) After electrophoresis, the gel shifted to Eagle Eye II picturedisposal system to measuring the light density of each product, and relative value of TIMP-3, MMP-3, Fas, Fas-L and Bcl-2.

Terminal deoxynucleotidyl Transferase Biotin-dUTP Nick End Labeling (TUNEL): TUNEL staining was carried out using the Apoptosis Detection Kit, (Beijing Zhongshan Biotechnoloy Engineering Co. Ltd.) in accordance to the protocol provided by the manufacturer. In short, slides were immersed in paraffin wax after which they were hydrated through alcohols of decreasing strength to $0.85 \% \mathrm{NaCl}$, and finally rinsed with PBS. The sections were fixed in a $4 \%$ methanolfree formaldehyde solution for $15 \mathrm{~min}$ and washed in PBS at room temperature. After this the slices were exposed to $20 \mu \mathrm{g} / \mathrm{ml}$ Proteinase $\mathrm{K}$ for $15-20 \mathrm{~min}$ at ambient temperature, rinsed twice (10min) with PBS, fixed in $4 \%$ methanol-free formaldehyde solution and incubated with POD for a $60 \mathrm{~min}$ at room temperature. Finally there was an incubation for $1 \mathrm{~h}$ in a dark humidity chamber at $37^{\circ} \mathrm{C}$ in $100 \mu \mathrm{l}$ of DAB incubation buffer whereafter the reaction was stopped using $2 \times$ standard sodium citrate and rinsed with PBS. Apoptosis cells were visualized using a fluorescence microscope.

Statistics analysis: Data are expressed as mean \pm standard deviation $(x \pm \mathrm{s})$. Statistical analysis was performed by one-way ANOVA (For Comparisons among multiple groups), LSD-t or Games-Howell (for comparisons between multi-samples averages and one group average) and two-tailed Pearson or Spearman(analysis of the two variables). Analyses were performed using SPSS for windows statistical soft ware (version11.5). 
Am. J. Immunol., 3 (2): 25-30, 2007

Table1. Primer Sequences and Expected PCR Products Sizes of TIMP-3, MMP-3, Fas, Fas-L, Bcl-2 and $\beta$-actin

\begin{tabular}{|c|c|c|c|}
\hline Primer & Primer Sequence & $\begin{array}{l}\text { Product } \\
\text { size }(\text { bp) }\end{array}$ & Reaction Condition \\
\hline TIMP-3 & $\begin{array}{l}\text { Sense ( 227-245 ) 5'-AGA TGC CCC ATG CGC AGT A-3' } \\
\text { anti Sense ( 506-525 ) 5'-GTA CCC GAA ATT GGA GAG CA-3' }\end{array}$ & 299 & $\begin{array}{l}95^{\circ} \mathrm{C} 5 \mathrm{~min}-\left[94^{\circ} \mathrm{C} 45 \mathrm{~s}-54^{\circ} \mathrm{C} 45 \mathrm{~s}-\right. \\
\left.72^{\circ} \mathrm{C} 50 \mathrm{~s}\right] \times 32 \text { cycle }-72^{\circ} \mathrm{C} 7\end{array}$ \\
\hline MMP-3 & $\min$ & & \\
\hline Fas & $\begin{array}{l}\text { Sense ( 1051-1070 ) 5'-CCG TCT CTT CCA TCC AAC AT-3' } \\
\text { antiSense ( 1456-1476 ) 5'-AAA CCA GCT GTT GCT CTT CAA-3' } \\
\text { min }\end{array}$ & 426 & $\begin{array}{l}95^{\circ} \mathrm{C} 5 \mathrm{~min}-\left[94^{\circ} \mathrm{C} 45 \mathrm{~s}-58^{\circ} \mathrm{C} 45 \mathrm{~s}-\right. \\
\left.72^{\circ} \mathrm{C} 60 \mathrm{~s}\right] \times 34 \text { cycle }-72^{\circ} \mathrm{C} 10\end{array}$ \\
\hline Fas-L & $\begin{array}{l}\text { Sense ( } 174-192) \text { 5'-CCG ACA ACA ACT GCT CAG A-3' } \\
\text { antiSense ( } 412-430 \text { ) 5'-GCA CCT GCA CTT GCT ATT C -3 }\end{array}$ & 257 & $\begin{array}{l}94^{\circ} \mathrm{C} 3 \mathrm{~min}-\left[94^{\circ} \mathrm{C} 30 \mathrm{~s}-53^{\circ} \mathrm{C} 45 \mathrm{~s}-\right. \\
\left.72^{\circ} \mathrm{C} 60 \mathrm{~s}\right] \times 35 \text { cycle }-72^{\circ} \mathrm{C} 7 \mathrm{~min}\end{array}$ \\
\hline Bcl-2 & $\begin{array}{l}\text { Sense ( 298-319 ) 5'-ATA GAG CTG TGG CTA CCG GTG-3' } \\
\text { antiSense ( 563-584 ) 5'-CTC CAG AGA TCA AAG CAG TTC C-3' }\end{array}$ & 287 & $\begin{array}{l}94^{\circ} \mathrm{C} 4 \mathrm{~min}-\left[94^{\circ} \mathrm{C} 60 \mathrm{~s}-60^{\circ} \mathrm{C} 60 \mathrm{~s}-\right. \\
\left.72^{\circ} \mathrm{C} 60 \mathrm{~s}\right] \times 32 \text { cycle }-72^{\circ} \mathrm{C} 7 \mathrm{~min}\end{array}$ \\
\hline$\beta$-actin & $\begin{array}{l}\text { Sense ( 294-312 ) 5'-TTA TAA GCT GTC ACA GAG G-3' } \\
\text { anti Sense ( 622-640 ) 5'-TGA AGA GTT CCT CCA CCA C-3' } \\
\text { min } \\
\text { Sense ( 400-419) 5'-GTA GCC ATC CAG GCT GTG TT-3' } \\
\text { anti Sense (1028-1047) 5'-CAG TGA GGC CAG GAT AGA GC- }\end{array}$ & 347 & $\begin{array}{l}94^{\circ} \mathrm{C} 3 \mathrm{~min}-\left[94^{\circ} \mathrm{C} 30 \mathrm{~s}-53^{\circ} \mathrm{C} 45 \mathrm{~s}-\right. \\
\left.72^{\circ} \mathrm{C} 45 \mathrm{~s}\right] \times 32 \text { cycle }-72^{\circ} \mathrm{C} 7\end{array}$ \\
\hline
\end{tabular}

\section{RESULTS}

Animal's neural function deflault and TTC staining analysis: All groups present focal cerebral ischemic behaviors after waking up from anaesthesia, such as: left forelimb bends, or left forelimb downwards and cannot be lifted once withdrawing the neck; turn around towards outside; topple over to the left side while walking. Rats' brain tissues from SOG are dyed by TTC staining, the results show the tissues were all dyed unanimous red and no infarct tissues found. However in ICG and IBG found some pale infarct tissues, which sizes are inconsistent, at the right side brain, the part whose distance is 7-11 $\mathrm{mm}$ away from olfactory bulb is most distinct, while the left side brain still presents red. In ischemic groups, the zone of ischemia is reliable and steady.

RT-PCR: The time course of TIMP-3, MMP-3, Bcl-2 and Fas-L expression was assessed in tissue extracts prepared from ICG, SOG and IBG. In the SOG the mRNA expression of TIMP-3, MMP-3, Bcl-2and Fac-L was detected, indicating its presence in normal tissues and Fac mRNA were absent. The results demonstrated that TIMP-3 mRNA was over expressed in ICG within 3 hours. After 3 hours of reperfusion TIMP-3 mRNA significantly increased. A second increase in mRNA was seen at 48 hours. Values of mRNA in the ICG were increased, but the rise at 3 hours and 48 hours in the IBG was more significant $(\mathrm{P}<0.01)$. The expression of TIMP-3 mRNA in ICZ was present, but to a lesser degree than
IPZ $(\mathrm{P}<0.01)$ and eventually peaked at $3 \mathrm{~h} . \quad$ MMP-3 mRNA expression was pronounced (ie, minimal) in IBG at o-12hours but predominantly at the $24 \mathrm{~h}$ time point after reperfusion compared with ICG $(\mathrm{P}<0.01)$ as shown in Table2. MMP-3 mRNA expression is similar in both IPZ and ICZ zone. We assessed the relationship of (Fas, Fas-1, and Bcl-2) mRNA expression in IBG.The expression of, Fas and Fas-1 mRNA was decreased but still higher than that of the ICG $(\mathrm{P}<0.01)$, while Bcl-2 mRNA increased as shown in Table2.

Changes of Apoptosis Positive Neurons: Apoptosis cells distribute mainly in ischemic penumbra zone. There were a small number of apoptosis positive cells in sham-operated group. In the ischemic zone, the neuronal apoptosis positive cells was detected and peaked at $3 \mathrm{~h}$ after reperfusion. By 6 hours of reperfusion, the neuronal apoptosis positive cells were decreased, reaching minimal levels by 72 hours. Neuronal apoptosis positive cells were significantly increased IBG in compared with ICG $(\mathrm{P}<0.01)$ as shown in Table2.

Relationship Between the Co-Expression of TIMP-3, MMP-3 and Apoptosis: In the IPZ, the expression of TIMP-3 mRNA shows positive correlation with the counts of apoptosis positive cells, while shows negative correlation with that of MMP-3 \& Fas-L mRNA. The expression of MMP-3 shows positive correlation with that of Bcl-2 mRNA. In ICZ, the expression of TIMP-3 mRNA showed positive 
Am. J. Immunol., 3 (2): 25-30, 2007

Table 2: mRNA Expression of TIMP-3, MMP-3, Fas, Fas-L, Bcl-2 and counts of apoptosis positive neurons (A+N) after MCAO with Various Times of Ischemia and Reperfusion $(x \pm \mathrm{s})$

\begin{tabular}{|c|c|c|c|c|c|c|c|c|c|c|}
\hline \multicolumn{3}{|c|}{ Group } & $\mathrm{SOG}$ & O3R0h & O3R3h & O3R6h & O3R12h & O3R24h & O3R48h & O3R72h \\
\hline \multirow{4}{*}{ 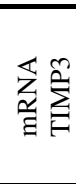 } & \multirow[b]{2}{*}{ Uِ } & IPZ & $0.70 \pm 0.07$ & $0.89 \pm 0.03^{\mathbf{\Lambda}}$ & $0.96 \pm 0.03^{\mathbf{\Lambda}}$ & $0.89 \pm 0.07^{\boldsymbol{\Lambda}}$ & $0.72 \pm 0.03$ & $0.63 \pm 0.07$ & $1.19 \pm 0.15^{\mathbf{X}}$ & $0.85 \pm 0.06^{\mathbf{X}}$ \\
\hline & & ICZ & $0.52 \pm 0.01$ & $0.82 \pm 0.03^{\boldsymbol{\Lambda}}$ & $0.89 \pm 0.07^{\mathbf{\Lambda}}$ & $0.75 \pm 0.04^{\boldsymbol{\Lambda}}$ & $0.66 \pm 0.08$ & $0.69 \pm 0.12^{\mathbf{\Lambda}}$ & $0.71 \pm 0.06^{\mathbf{\Lambda}} \mathbf{\Lambda}$ & $0.68 \pm 0.07^{\mathbf{\Lambda}}$ \\
\hline & \multirow[b]{2}{*}{$\cong 0$} & IPZ & & & $0.79 \pm 0.14^{* *}$ & $0.65 \pm 0.12^{* *}$ & $0.64 \pm 0.08$ & $0.60 \pm 0.07$ & $0.88 \pm 0.11^{* *}$ & $0.80 \pm 0.06^{* *}$ \\
\hline & & ICZ & & & $0.74 \pm 0.03^{* *}$ & $0.65 \pm 0.04$ & $0.66 \pm 0.07$ & $0.68 \pm 0.09$ & $0.83 \pm 0.14^{*}$ & $0.74 \pm 0.10$ \\
\hline \multirow{4}{*}{ 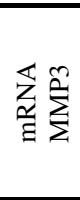 } & \multirow[b]{2}{*}{ نِ } & IPZ & $0.60 \pm 0.06$ & $0.47 \pm 0.03$ & $0.47 \pm 0.01$ & $0.38 \pm 0.03^{\boldsymbol{\Lambda \Lambda}}$ & $0.56 \pm 0.02^{\mathbf{\Lambda}}$ & $0.80 \pm 0.09^{\mathbf{\Lambda}}$ & $0.49 \pm 0.05$ & $0.36 \pm 0.07^{\mathbf{X}}$ \\
\hline & & ICZ & $0.66 \pm 0.03$ & $0.53 \pm 0.08$ & $0.47 \pm 0.01^{\mathbf{\Lambda}} \mathbf{\Lambda}$ & $0.43 \pm 0.01^{\boldsymbol{\Lambda}}$ & $0.81 \pm 0.05$ & $0.50 \pm 0.03^{\mathbf{\Lambda} \Delta}$ & $0.51 \pm 0.04^{\boldsymbol{\Lambda}}$ & $0.37 \pm 0.03^{\boldsymbol{\Lambda}}$ \\
\hline & \multirow{2}{*}{$\cong 0$} & IPZ & & & $0.46 \pm 0.06$ & $0.57 \pm 0.04^{* *}$ & $0.43 \pm 0.03^{* *}$ & $0.44 \pm 0.03^{* *}$ & $0.45 \pm 0.04$ & $0.71 \pm 0.04^{* *}$ \\
\hline & & ICZ & & & $0.48 \pm 0.04$ & $0.75 \pm 0.05^{* *}$ & $0.66 \pm 0.03$ & $0.53 \pm 0.01$ & $0.64 \pm 0.04 *$ & $0.55 \pm 0.05^{*}$ \\
\hline \multirow{4}{*}{ 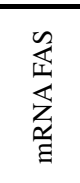 } & \multirow[b]{2}{*}{$\underline{U}$} & IPZ & $0.00 \pm 0.00$ & $0.39 \pm 0.03^{\boldsymbol{\Lambda \mathbf { X }}}$ & $0.50 \pm 0.01^{\boldsymbol{\Lambda \mathbf { \Lambda }}}$ & $0.61 \pm 0.05^{\boldsymbol{\Lambda}}$ & $0.55 \pm 0.03^{\boldsymbol{\Lambda \mathbf { X }}}$ & $0.45 \pm 0.04^{\boldsymbol{\Lambda \Lambda}}$ & $0.00 \pm 0.00$ & $0.00 \pm 0.00$ \\
\hline & & ICZ & $0.00 \pm 0.00$ & $0.42 \pm 0.03^{\boldsymbol{\Delta}}$ & $0.50 \pm 0.01^{\boldsymbol{\Lambda}}$ & $0.47 \pm 0.03^{\boldsymbol{\Delta}}$ & $0.58 \pm 0.03^{\mathbf{\Lambda}}$ & $0.48 \pm 0.04$ & $0.00 \pm 0.00$ & $0.00 \pm 0.00$ \\
\hline & \multirow{2}{*}{$\cong 0$} & IPZ & & & $0.30 \pm 0.03^{* *}$ & $0.42 \pm 0.02^{* *}$ & $0.43 \pm 0.02^{* *}$ & $0.40 \pm 0.03$ & $0.00 \pm 0.00$ & $0.00 \pm 0.00$ \\
\hline & & $\mathrm{ICZ}$ & & & $0.38 \pm 0.03 *$ & $0.40 \pm 0.03$ & $0.46 \pm 0.05^{*}$ & $0.43 \pm 0.13$ & $0.00 \pm 0.00$ & $0.00 \pm 0.00$ \\
\hline \multirow{4}{*}{ 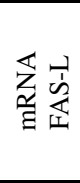 } & \multirow{2}{*}{ Uِ } & $\overline{I P Z}$ & $0.36 \pm 0.04$ & $0.32 \pm 0.02$ & $0.41 \pm 0.09$ & $0.78 \pm 0.12^{\mathbf{A}}$ & $0.42 \pm 0.06$ & $0.46 \pm 0.03$ & $0.79 \pm 0.05^{\mathbf{\lambda}}$ & $0.67 \pm 0.05^{\mathbf{\lambda}}$ \\
\hline & & ICZ & $0.33 \pm 0.02$ & $0.31 \pm 0.02$ & $0.30 \pm 0.01$ & $0.63 \pm 0.10^{\Perp}$ & $0.52 \pm 0.07^{\mathbf{\Delta}}$ & $0.40 \pm 0.02^{凶}$ & $0.32 \pm 0.02$ & $0.23 \pm 0.03$ \\
\hline & \multirow{2}{*}{$\cong 0$} & IPZ & & & $0.26 \pm 0.05$ & $0.28 \pm 0.03^{* *}$ & $0.35 \pm 0.03$ & $0.27 \pm 0.03^{* *}$ & $0.00 \pm 0.00^{* *}$ & $0.00 \pm 0.00^{* *}$ \\
\hline & & $\mathrm{ICZ}$ & & & $0.27 \pm 0.03$ & $0.41 \pm 0.03$ & $0.34 \pm 0.03^{*}$ & $0.45 \pm 0.03$ & $0.00 \pm 0.00^{* *}$ & $0.00 \pm 0.00^{* *}$ \\
\hline \multirow{4}{*}{ 范筧 } & \multirow{2}{*}{ ט } & IPZ & $0.83 \pm 0.06$ & $0.82 \pm 0.04$ & $0.73 \pm 0.04$ & $0.62 \pm 0.04^{\boldsymbol{\Lambda} \Lambda}$ & $0.53 \pm 0.08^{\mathbf{\Lambda}}$ & $0.83 \pm 0.18$ & $1.00 \pm 0.06$ & $0.80 \pm 0.07$ \\
\hline & & $\mathrm{ICZ}$ & $0.84 \pm 0.03$ & $0.81 \pm 0.05$ & $0.60 \pm 0.07^{\boldsymbol{\Lambda}}$ & $0.58 \pm 0.05^{\boldsymbol{\Lambda}} \mathbf{\Lambda}$ & $0.53 \pm 0.09^{\mathbf{\Lambda}}$ & $0.64 \pm 0.07^{\boldsymbol{\Lambda}}$ & $0.92 \pm 0.11$ & $0.77 \pm 0.05$ \\
\hline & \multirow{2}{*}{$\cong 0$} & IPZ & & & $0.67 \pm 0.04$ & $0.75 \pm 0.04^{*}$ & $0.76 \pm 0.05^{*}$ & $0.64 \pm 0.04$ & $0.75 \pm 0.07^{*}$ & $1.04 \pm 0.08^{*}$ \\
\hline & & ICZ & & & $0.87 \pm 0.04^{* *}$ & $0.93 \pm 0.06^{* *}$ & $1.02 \pm 0.11^{* *}$ & $0.67 \pm 0.07$ & $1.06 \pm 0.14^{* *}$ & $0.85 \pm 0.05$ \\
\hline \multirow{4}{*}{ Z } & \multirow{2}{*}{ نِ } & IPZ & $6.20 \pm 1.48$ & $\begin{array}{c}123.4 \pm 6.02 \\
\mathbf{\Lambda}\end{array}$ & $\begin{array}{c}206.4 \pm 19.0 \\
\mathbf{\Lambda \Lambda}\end{array}$ & $\begin{array}{c}154.0 \pm 10.0 \\
\mathbf{\Lambda}\end{array}$ & $\begin{array}{c}129.6 \pm 4.04 \\
\mathbf{\Delta}\end{array}$ & $\begin{array}{c}114.2 \pm 10.3 \\
\mathbf{\Lambda}\end{array}$ & $\begin{array}{c}107.0 \pm 4.06 \\
\mathbf{\Delta}\end{array}$ & $\begin{array}{c}84.2 \pm 5.26 \\
\boldsymbol{\Lambda}\end{array}$ \\
\hline & & ICZ & $6.40 \pm 1.14$ & $\underset{\mathbf{\Delta \Delta}}{65.0 \pm 4.85}$ & $\underset{\mathbf{\Delta}}{98.8 \pm 1.92}$ & $\begin{array}{c}82.8 \pm 8.47 \\
\mathbf{\Delta \Lambda}\end{array}$ & $\underset{\mathbf{\Delta \Delta}}{76.0 \pm 4.06}$ & $\underset{\mathbf{\Delta}}{60.0 \pm 5.15}$ & $\underset{\mathbf{\Delta \Lambda}}{43.6 \pm 5.90}$ & $\underset{\mathbf{\Delta}}{32.6 \pm 6.69}$ \\
\hline & \multirow{2}{*}{ ర్ } & IPZ & & & $\begin{array}{c}117.6 \pm 23.3 \\
* *\end{array}$ & $\begin{array}{c}82.0 \pm 13.67 \\
* *\end{array}$ & $\begin{array}{c}71.6 \pm 11.3 \\
* *\end{array}$ & $\begin{array}{c}64.4 \pm 10.48 \\
* *\end{array}$ & $\begin{array}{c}55.0 \pm 5.15 \\
* *\end{array}$ & $\begin{array}{c}34.4 \pm 5.41 \\
* *\end{array}$ \\
\hline & & ICZ & & & $\begin{array}{c}73.0 \pm 5.57 \\
* *\end{array}$ & $\begin{array}{c}59.4 \pm 6.58 \\
* *\end{array}$ & $\begin{array}{c}40.2 \pm 4.44 \\
* *\end{array}$ & $\begin{array}{c}37.60 \pm 7.57 \\
* *\end{array}$ & $37.40 \pm 2.61$ & $32.80 \pm 5.07$ \\
\hline
\end{tabular}

Each time point of ICG compared with SOG: $\Delta \mathrm{P}<0.05, \Delta \Delta \mathrm{P}<0.01$; time points of IBG compared with ICG: $* \mathrm{P}<0.05, * * \mathrm{P}<0.01$.

Table3: Correlation between mRNA expression of TIMP-3, MMP-3, FAS, FAS-L, BCL-and the counts of apoptosis positive neurons

\begin{tabular}{|c|c|c|c|c|c|c|}
\hline \multirow{2}{*}{$\begin{array}{c}\text { Variable index } \\
\text { R value }\end{array}$} & \multicolumn{2}{|c|}{ TIMP-3 mRNA } & \multicolumn{2}{|c|}{ MMP-3 mRNA } & \multicolumn{2}{|c|}{ Counts of apoptosis cells } \\
\hline & PZ (P value) & $\mathrm{CZ}$ (Pvalue) & PZ (P value) & CZ (Pvalue) & PZ (P value) & $\mathrm{CZ}$ (P value) \\
\hline MMP-3mRNA & $-0.307(0.010)$ & $-0.244(0.04)$ & & & & \\
\hline FAS mRNA & $0.394(0.000)$ & $0.335(0.008)$ & & & $0.492(0.000)$ & $0.529(0.000)$ \\
\hline FAS-L mRNA & $0.283(0.027)$ & & & & $0.364(0.000)$ & $0.280(0.001)$ \\
\hline BCL-2 mRNA & $0.332(0.005)$ & & $0.315(0.009)$ & & & \\
\hline $\mathrm{A}+\mathrm{N}$ & $0.337(0.004)$ & $0.366(0.001)$ & $0.315(0.011)$ & $0.294(0.024)$ & & \\
\hline
\end{tabular}


correlation with the counts of apoptosis positive cells, and showed negative correlation with that of Fas-L mRNA. The expression of MMP-3 mRNA showed positive correlation with that of Bcl-2 mRNA. In ischemic zone, Fas \& Fas-L mRNAs showed positive correlation with the account of apoptosis positive cell, while the expression of Bcl-2 mRNA showed negative correlation as shown in Table3.

\section{DISCUSSION}

We found marked TIMP-3 expression in neurons in ischemic zone. TIMP-3 alone appears insufficient to initiate cell death because it was seen in neuronal process in normal tissues. The present studies indicate that after focal ischemia there are marked differences in the expression of TIMP-3 and MMP-3 at the ischemic site. TIMP-3 showed expression as early as 0 hours after initiation of reperfusion, and maximal expression appeared at 3hours and 48 hours. MMP-3 was decreased at 0-12 hours and peaked at 24 hours. Our finding of the colocalization of TIMP-3 ischemic neurons suggests a role of TIMP-3 in cell death in the brain. Expression of the TIMP-3 mRNA was seen in both Ishemic and normal tissue, while the PT-PCR showed an increase in protein only on the ischemic tissues. The increase in TIMP-3 protein at 3 and 48 hours was consistent with induction. One possibility is that the TIMP-3 was bound to the MMPs that are inreased by 24 hours after reperfusion, resulting in a higher molecular-weight complex. These results show that MMPs and TIMPs are dramatically affected by reperfusion but contribute in a complex manner to reperfusion injury. Matrix-degrading proteases are important in many normal and pathological processes, including motility of developing. Tissue inhibitor of metalloproteinase-3 was found in normal tissues, suggesting that other factors are needed along with TIMP-3 to promote cell death. Although further studies will be necessary to resolve the effect on the normal tissue, the results of the mRNA, provide convincing support for an increase in TIMP-3 on the ischemic zone This is consistent with reports of TIMP-3 gene expression in brain injury and in Wobbler mice ${ }^{[10,11]}$. Programmed cell death occurs by release of caspaseactivating factors from mitochondria or by the stimulation of cell surface receptors that may or may not act through mitochondrial activation ${ }^{[12]}$. These are referred to as the intrinsic and extrinsic pathways ${ }^{[13]}$. Previous studies have suggested that TIMP-3 acts through cell surface receptors. The mechanism proposed is that TIMP-3 and inhibits MMPs that are involved in the shedding of the DRs and DILs from the cell surface ${ }^{[14,15]}$. Proposed sheddases include MMP-3, MMP-7, ADAM- 10, and ADAM-17. Sheddases release either the DRs or the DILs from the cell surface, and, depending on the cell types and the substrate released, the sheddases can play a protective or damaging role ${ }^{[16,17]}$ Death receptors include the members of the TNF superfamily, such as Fas. One study showed that inhibition of the sheddases -L, etc. All genes can promote apoptosis except $\mathrm{Bcl}-2$, who plays a role in inhibit apoptosis. Inhibition mecahinsm includes that MMP-3 can hydrolysises cell's surface death receptor and death ligands directly which will suppress apoptosis, and also activating phospholipase A2 through Bcl-2 which would suppress Fas-induced apoptosis, and producing inhibition through type II apoptosis. . More important, that TIMP-3 and MMP-3 express by TIMP-3 stabilized TNF receptors on the cell surface, promoting cell death ${ }^{[18]}$. Fas ligand and Fas receptors are associated with cell death in ischemic neurons. Mice lacking the Fas ligand gene have smaller strokes. In the same study ${ }^{[19]}$ it was shown that the anticancer drug, doxorubicin, induces the Fas ligand in cultured neurons and leads to apoptosis of the cells.

We have studied the role of TIMP-3, MMP-3 and apoptosis gen in neuronal cell. We found that the occurrence of cell apoptosis after focal cerebral ischemia-reperfusion is an active death progress controlled by multi-genes, which usually include: $\mathrm{Bcl}-2$, Fas, Faspersistently in neurons and the expression activity of neuron surface. TIMP-3 \& MMP-3 can modulate DRs' sensitivity and might regulate neuron apoptosis ${ }^{[20]}$.

\section{CONCLUSION}

Our results suggest that the balance between the MMP3 , TIMP-3 and apopotosis gen play a role in ischemicreperfusion injury. Inhibition of the metalloproteinases altered the early damage to the brain tissue. MMP- 3 and TIMP-3 might modulate the process of type I and type II neuronal apoptosis through FAS pathway. Sodium aescinat have benifical effect on relation between TIMP-3, MMP-3 and neural apoptosis gen.

\section{REFERENCES}

1. Raoul C, Pettmann B and HendersonCE,2000.Active killing of neurons during development and following stress: a role for p75 (NTR) and Fas? Curr Opin Neurobiol, 10:111117. 
2. Cheema ZF, Wade SB and Sata M, 1999. Fas/Apo [apoptosis]-1 and associated proteins in the differentiating cerebral cortex: induction of caspase-dependent cell death and activation of NFkappaB. J Neurosci, 19:1754

3. Levy DE, Brott TG, Haley EC Jr, Marler JR, Sheppard GL, Barsan W and Broderick JP, 1994. Factors related to intracranial hematoma formation in patients receiving tissue-type plasminogen activator for acute ischemic stroke. Stroke. 25:291297

4. 1770Del Zoppo GJ, Copeland BR, Anderchek K, Hacke $W$ and Koziol JA. Hemorrhagic transformation following tissue plasminogen activator in experimental cerebral infarction, 1990. Stroke, 21:596-601.

5. Schlondorff J and Blobel CP, 1999. Metalloprotease-disintegrins: modular proteins capable of promoting cell-cell interactions and triggering signals by protein-ectodomain shedding. J Cell Science, 112:3603-3617.

6. Woessner JF, 1998. The matrix metalloproteinase family. In: Parks WC, Mecham RP, eds. Matrix Metalloproteinases. San Diego, Calif: Academic Press, 1-13.

7. Powell WC, Fingleton B and Wilson CL, 1999. The metalloproteinase matrilysin proteolytically generates active soluble Fas ligand and potentiates epithelial cell apoptosis. Curr Biol, 9:1441-1447.

8. Bond M, Murphy G, Bennett MR, et al, 2002. Tissue inhibitor of metalloproteinase-3 induces a Fas-associated death domain- dependent type II apoptotic pathway. J Biol Chem, 277 (16): 1378713795.

9. Longa EZ, Weinstein PR, Carlson S and Cummins R, 1989. Reversible middle cerebral artery occlusion without craniectomy in rats. Stroke, 20: 84-91.

10. Jaworski DM, 2000. Differential regulation of tissue inhibitor of metalloproteinase mRNA expression in response to intracranial injury. Glia, 30:199-208.

11. Rathke-Hartlieb S, Budde P, Ewert S, Schlomann U, Staege MS, Jockusch H, Bartsch JW and Frey J, 2000. Elevated expression of membrane type 1 metalloproteinase (MT1-MMP) in reactive astrocytes following neurodegeneration in mouse central nervous system. FEBS Lett, 481:227-234.
12. Ashkenazi A and Dixit VM, 1998. Death receptors: signaling and modulation. Science, 281:1305-1308.

13. Graham SH and Chen J, 2001. Programmed cell death in cerebral ischemia. J Cereb Blood Flow Metab, 21:99-109.

14. Amour A, Slocombe PM, Webster A, Butler M, Knight CG, Smith BJ, Stephens PE, Shelley C, Hutton M, Knauper V, Docherty AJ and Murphy G, 1998. TNF__ converting enzyme (TACE) is inhibited by TIMP-3. FEBS Lett, 435:39-44.

15. Amour A, Knight CG, Webster A, Slocombe PM, Stephens PE, Knauper V, Docherty AJ and Murphy $\mathrm{G}$, 2000.The in vitro activity of ADAM-10 is inhibited by TIMP-1 and TIMP-3. FEBS Lett, 473:275-279.

16. Powell WC, Fingleton B, Wilson CL, Boothby M, Matrisian LM, 1999. The metalloproteinase matrilysin proteolytically generates active soluble Fas ligand and potentiates epithelial cell apoptosis. Curr Biol, 9:1441-144.

17. Matsuno H, Yudoh K, Watanabe Y, Nakazawa F, Aono $\mathrm{H}$ and Kimura T, 2001. Stromelysin-1 (MMP-3) in synovial fluid of patients with rheumatoid arthritis has potential to cleave membrane bound Fas ligand. J Rheumatol, 28:2228.

18. Smith MR, Kung H, Durum SK, Colburn NH and Sun Y, 1997. TIMP-3 induces cell death by stabilizing TNF-alpha receptors on the surface of human colon carcinoma cells. Cytokine, 9:770-780

19. Martin-Villalba A, Herr I, Jeremias I, Hahne M, Brandt R, Vogel J, Schenkel J, Herdegen T and Debatin KM, 1999. CD95 ligand (Fas- L/APO-1L) and tumor necrosis factor-related apoptosisinducing ligand mediate ischemia-induced apoptosis in neurons. J Neurosci, 19:3809-3817

20. Wetzel M, Rosenberg_GA and Cunningham LA, 2003. Tissue inhibitor of metalloproteinases-3 and matrix metalloproteinase-3 regulate neuronal sensitivity to doxorubicin-induced apoptosis. Eur J Neuroscience, 18: 1050-1060. 